\title{
SHADE AND TEXTURE MAPPING ON TEETH FOR PALAEOANTHROPOLOGICAL RECONSTRUCTIONS
}

\author{
A.V. Gaboutchian ${ }^{1 *}$, V. A. Knyaz $^{2,3}$, S.V. Apresyan ${ }^{1}$, M.S. Navrazhnykh ${ }^{1}$, S.V. Vasyliev ${ }^{4}$ \\ ${ }^{1}$ Peoples Friendship University of Russia, 117198, Moscow, Russia armengaboutchian@mail.ru; dr.apresyan@gmail.com \\ ${ }^{2}$ State Research Institute of Aviation System (GosNIIAS), 125319 Moscow, Russia - knyaz@gosniias.ru \\ ${ }^{3}$ Moscow Institute of Physics and Technology (MIPT), Dolgoprudny, Russia \\ ${ }^{4}$ Institute of Ethnology and Anthropology RAS, Moscow, Russia - vasbor1 @ yandex.ru
}

\section{Commission II, WG II/10}

KEY WORDS: 3D reconstruction, 3D surface analysis, 3D prototyping, odontology

\begin{abstract}
:
Over the past few years closer cooperation can be observed in various aspects of digital techniques in such disciplines as dentistry and anthropology. And in most cases that consists in imaging and image processing which results in obtaining 3D reconstructions. And indeed, they can significantly improve research and practice. Thus, depending on imaging technique and application, they can support CAD/CAM technology or precisely reconstruct morphology of invisible structures. However the currently presented study refers to technical aspects of shade and texture mapping, which is more aimed to obtain more realistic 3D reconstructions of palaeoanthropological material. Colour or shade matching has become an integral part of dental practice. It can be carried in a traditional manner though matching the tooth with conventional shade-guides, or, which is in line with the subjects of our study, by means of spectrophotometry. And the main procedures of shade detection have been performed by SpectroShade (MHT). Necessary attention has been paid to conditions influencing shade detection process with respect to the studied material teeth taken from the Bronze Age findings. Reconstructive techniques have traditionally been a scientific and practical part of palaeoanthropological research which is directed at appearance reconstruction. Though the leading part of this branch has been always aimed at analysis of skull morphology. In our time of rapidly developing digital techniques reconstructions have become to a large extent a matter of improvements of imaging and image processing techniques. Even though this doesnt directly refer to soft tissue reconstruction, it undoubtedly applies to dental reconstructions. And the current study presents improvements in reconstruction through combining imaging with shade and texture mapping on 3D models of teeth.
\end{abstract}

\section{INTRODUCTION}

Dental studies have become more intense over the period of recent years in terms and through cooperation between different scientific and practical disciplines. Each of them, having their own vector of development, reaches a certain level which is being sought with interest after colleagues working in parallel directions. Thus various techniques, methods, interpretations can be transferred from dentistry to anthropology and vice versa. And quite often, especially taking into consideration rapid advances in digital techniques, the connecting link is provided by $3 \mathrm{D}$ imaging and image processing. They improve many aspects in practical dentistry as well as in anthropological and dental research. And the focus is usually concentrated on obtaining accurate, highresolution reconstructions. This is undoubtedly important from technological point of view (Beyer, 2019) or in terms of detailed reconstruction of the smallest structures which are necessary for studies or methodological improvements (Gaboutchian et al., 2020 b). Nevertheless there are other aspects which come to the fore in order to add value to traditional workflow. And this can be illustrated once again by the current study where shade matching methodology and technology developed for practical applications in dentistry has been transferred to reconstruct palaeoanthropological material.

Reconstruction, in general, has become an integral part of phys-

\footnotetext{
${ }^{*}$ Corresponding author
}

ical anthropology as skeletal remains, which represent the major share of findings, usually preserve necessary signs for interpreting soft tissue morphology. Thus there is a traditional scientific and practical discipline in palaeoanthropology facial reconstruction, which is based in particular on the analysis of skull morphology (Gerasimov, 1955). In line with skeletal structures, teeth provide important information for various sides of palaeoanthropological studies. Their morphological features, functioning changes taking place throughout life, pathological conditions and ability to preserve genetic information serve for different interpretations regarding taxonomic, evolutionary, historical and other aspects of anthropological research (Zubov, 1968; Irish and Scott, 2015). In addition they are resistant to destructive influence of environmental conditions as are composed of highly mineralized tissues. Today the above-mentioned skeletal and especially dental palaeoanthropological material has a tendency to be reconstructed digitally, which provides for advances in study methods and technology as well as improves the workflow (Naidu and Freer, 2013).

3D imaging and techniques have a good potential to improve palaeoanthropological and palaeodontological research in different aspects including reconstruction (Gaboutchian et al., 2020a), (Knyaz, 2020). And the issue of interest in the current study is in combining 3D shape reconstructions of teeth with shade and texture reconstruction, which is an important aspect for achieving realistic similarity. The study was performed on Neolithic 
palaeoanthropological findings. Their 3D reconstructions were obtained by optical scanning by means of intra-oral scanner designed for chair-side use. Spectrophotometric devices were used for detailed colour mapping and comparison of shade detecting results.

\section{RELATED WORKS}

Shade matching is an important aspect of various clinical and technical procedures in dentistry. And it continuously remains an issue under discussion and research in prosthetic dentistry, aesthetic dentistry and in chair-side and laboratory workflow (Morgan, 2012; Joiner and Luo, 2017). Traditionally the shade matching has been a matter of comparison of natural teeth with standard shade guides, such as Chromascop by Ivoclar Vivadent, Vita Classical, Vita Bleachguide 3D Master and Vita Toothguide 3D Master by VITA Zahnfabrik and others. Such an approach can work effectively in the majority of cases however being dependant on various subjective and objective factors (Agrawal and Kapoor, 2013). To large extent correct shade choice results are determined by the degree of matching of optical properties of real tooth with conventional colour scales. And this is not only a matter of colour (Joiner, 2004). There are many factors and, for instance, translucency of teeth plays a significant role as they are composed of layers of tissues with different optical density.

Thus dental enamel thickness can determine optical features of teeth (He et al., 2019). In addition dental tissues have a tendency to change throughout life. Thus this correlates with studies of tooth colour are conducted in relevance to colour of skin, age or sex (Susanty et al., 2018). However results of similar studies can vary from one case to another and probably their consistency depends on different factors such as analysed population (Lagouvardos et al., 2012; Al-Nsour et al., 2018; Tancu et al., 2019). It is worth mentioning that soft tissue colourimetry is a matter of study in dentistry as well, and this can be a feature to consider in anthropological reconstruction in line with dental shade study results (Hyun et al., 2016).

In addition there are other external conditions which have an impact on the process of colour matching. Such factors as light source or tooth surface moisture usually have their effect on reflective properties of dental enamel. Daylight has been traditionally considered optimal in providing closest shade matching. However today artificial lighting and mobile cameras are more often used as a way to facilitate communication within dental community (Soldo et al., 2020). Dried-up surfaces of teeth and insufficiency of illumination spectrum are hindering factors for correct colour detection (Shereen and Sameh, 2020).

Nevertheless, even under the right conditions, the traditional colour matching procedure preserves a certain degree of subjectivity as colour perception remains an individual feature (Shooriabi et al., 2016). Thus in recent decades a number of devices improving and facilitating shade matching in dentistry have been designed (Brewer et al., 2004; Al-Dwairi et al., 2014). Thus conventional spectrometers and spectrophotometers are a better match for digital reconstructions of teeth which represent our study material. Being designed for application in practical dentistry, these devices reproduce conventional shade guides units as measurement results.

\section{MATERIALS AND METHODS}

Teeth representing the material for the current study were taken from two skulls (adult skull VIII-7-2 and adolescent VIII-58) from Chernovaya craniological series including more than 50 pieces. These burials 14 kurgans are located in the Republic of Khakassia and Krasnyarskiy Krai (Russian Federation). Dating back to the second millennium BC (Bronze Age of that region) they belong to culture well-known in anthropology as Okunev (Figure 1).

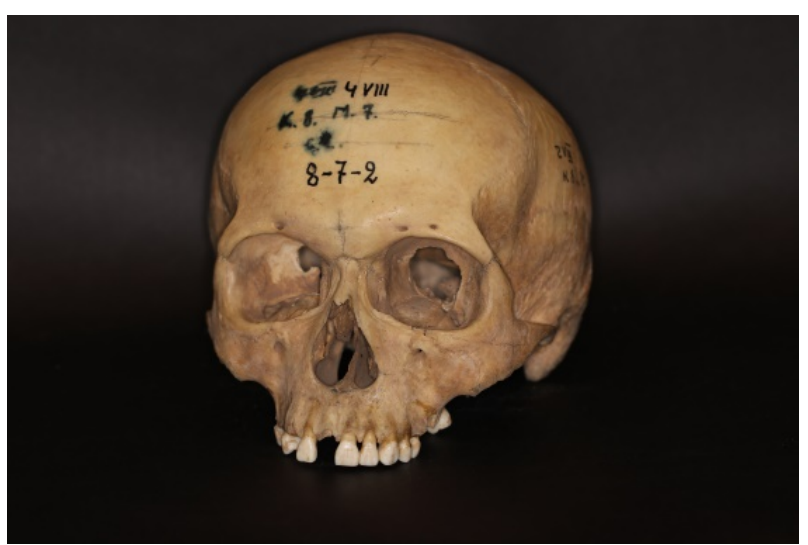

(a) Chernovaya VIII-7-2

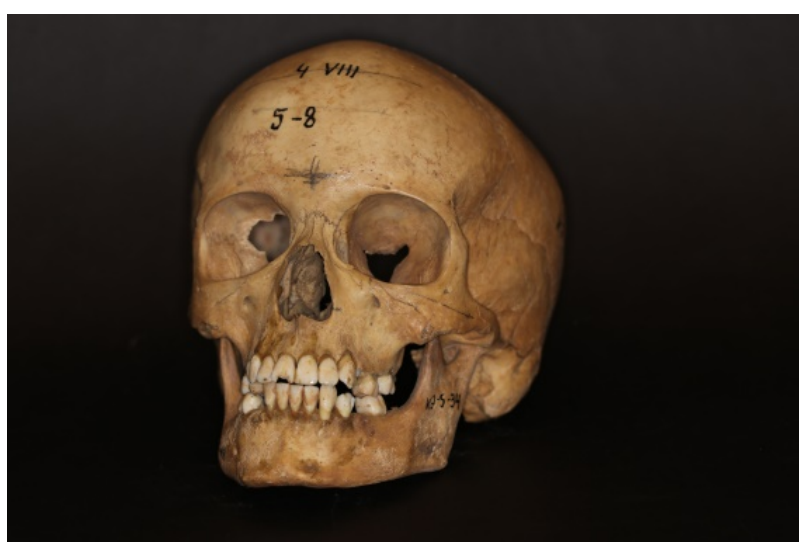

(b) Chernovaya VIII-5-8

Figure 1. Skulls VIII-7-2 (a) and VIII-5-8 (b), Chernovaya.

Our first attempt for shade matching by two different spectrophotometric devices: Vita EasyShade (Vita Zahnfabrik) and SpectroShade (MHT) brought to inconsistent results, which are presented according to two standard shade-guides: Vita Classic and Vita 3D Master (Table 1). The mentioned evident inconsistency referred to results obtained on two different devices; however both devices show results clearly differing from teeth on the chosen samples (Figure 2a,b).

\begin{tabular}{|l|ll|ll|}
\hline & \multicolumn{2}{|c|}{ VIII-5-8 } & \multicolumn{2}{c|}{ VIII-7-2 } \\
\hline & $\begin{array}{l}\text { Vita } \\
\text { Classic }\end{array}$ & $\begin{array}{l}\text { Vita 3D } \\
\text { Master }\end{array}$ & $\begin{array}{l}\text { Vita } \\
\text { Classic }\end{array}$ & $\begin{array}{l}\text { Vita 3D } \\
\text { Master }\end{array}$ \\
\hline SpectroShade & A1 & 0M1 & A1 & 0M1 \\
\hline Vita Easyshade & A3,5 & 3M3 & A3,5 & 4M3 \\
\hline
\end{tabular}

Table 1. Shade matching results by two instruments 


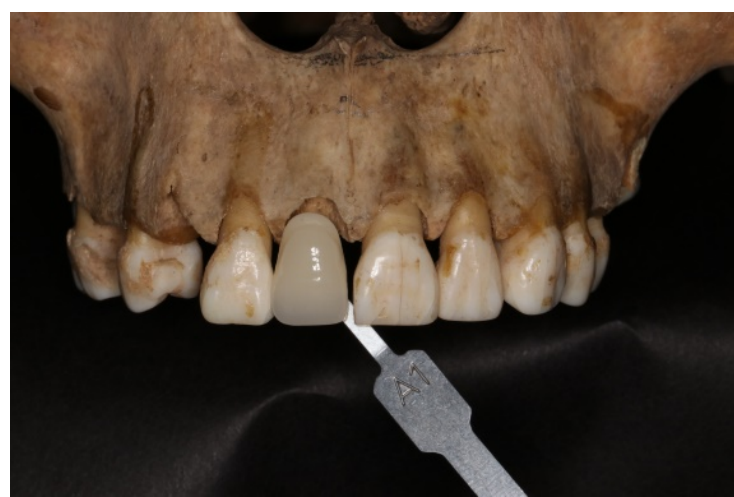

(a) SpectroShade

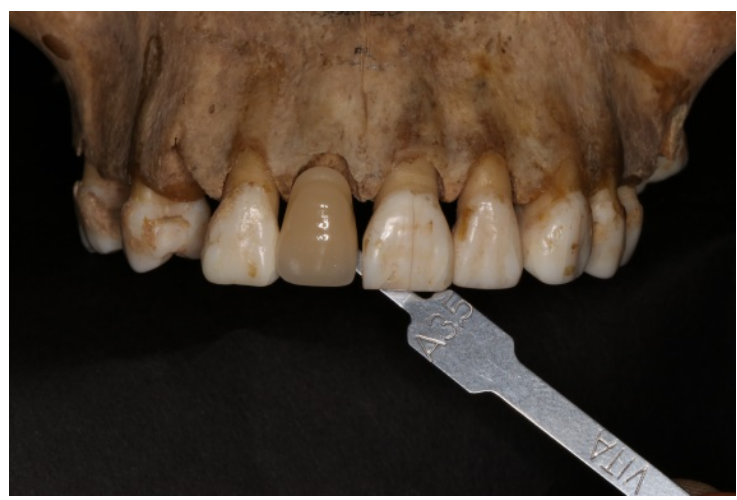

(b) Vita EasyShade

Figure 2. Vita Classic shade-guide samples positioned according to colour matching by SpectroShade (a) and Vita EasyShade (b); skull VIII-7-2.

Thus it was decided to use more profound methodology. Three teeth (all of them incisors) were removed from the sockets, which, due to their root shape, was a rather simple manipulation and didnt cause damage to the findings. Two of them upper right second incisor and upper left first incisor are from VIII-7-2 sample; from VIII-5-8 sample only one incisor was taken the upper left first incisor. All these teeth were placed in saline and were kept for more than three days in the solution to become completely drenched.

Shade detection procedure was carried out on separate teeth twice: on dry samples and after their drenching. For this stage of the study SpectroShade (MHT) instrument was picked as providing more ample and realistic data (Figure 3).

Results according to Vita Classic shade-guide are presented in Table 2.

\begin{tabular}{|l|c|c|c|}
\hline & 2.1, VIII-5-8 & 1.2, VIII-7-2 & 2.1, VIII-7-2 \\
\hline dry & A2 & A1 & A1 \\
\hline drench & A3 & A2 & A2 \\
\hline
\end{tabular}

Table 2. Differences of shades on dry and saturated samples

\section{RESULTS AND DISCUSSION}

Combining techniques implemented in disciplines which are different in terms of methodologies and study aspects, however at

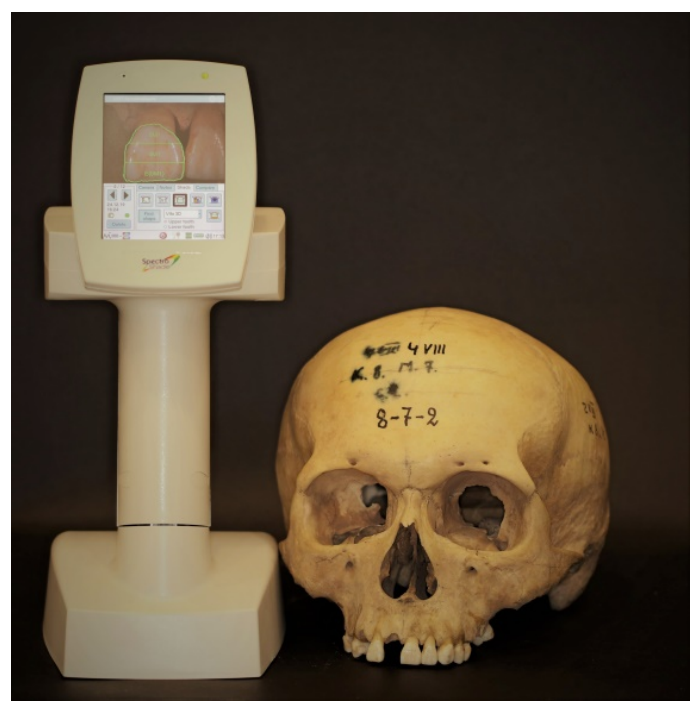

Figure 3. Studied sample spectrophotometric colour assessment.

the same time are focused at similar objects, has a potential to result in new advances and outcomes.

Thus digital techniques have given new impetus for development of dental technology and anthropological research through introducing different imaging and image processing techniques. However there is significantly larger sphere of methodological improvements resulting from inter-disciplinary exchange of techniques and ideas. And the currently presented study which deals with shade matching and its application in palaeoanthropology is an example of such cooperation.

\subsection{Shade matching}

Shade matching, especially regarding teeth which are composed of layers of tissues varying in shade and translucency, is a complex procedure. It has been traditionally performed through comparative selection of the most appropriate sample from standard shade guides according in accordance with the studied tooth. However spectrophotometry can improve objectivity in performing such tasks. Colour assessment on palaeoanthropological findings for further reconstructions has its characteristic features; and dried out tissues are one of them.

It should be emphasized that the studied sample drenching has led to consistent increase of colour saturation, decrease of translucency and other aspects determining optical features of teeth which can be detected through spectrophotometry (Figure 4, 5).

In addition the data obtained spectrophotometrically can be combined with $3 \mathrm{D}$ reconstructions of teeth. Some intra-oral scanners provide textured reconstructions of teeth, dentures and soft tissues which are provided by original software and corresponding file formats, including the scanner we have been using in the study. Nevertheless 3D reconstructions of teeth are obtained through significantly wider range of imaging techniques and the majority of them, especially those providing high-resolutions do not imitate texture and colour.

\subsection{Photorealistic texturing}

In addition a wide spectrum of studies is performed in anthropology on 3D reconstructions in file formats (such as .stl) which are 


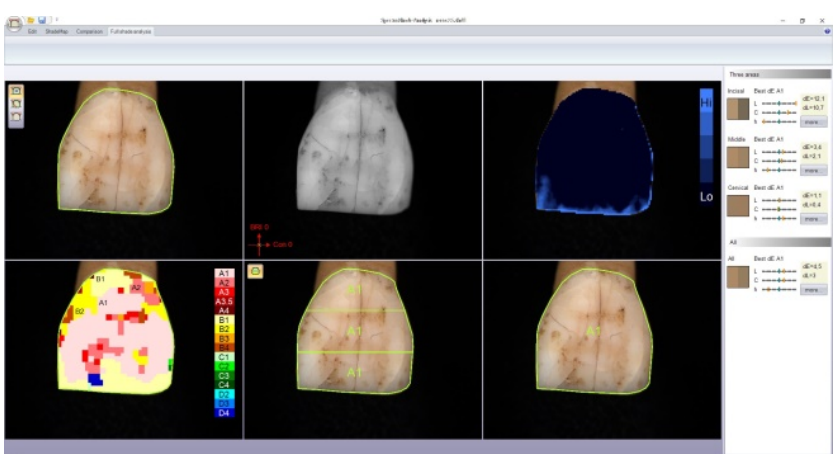

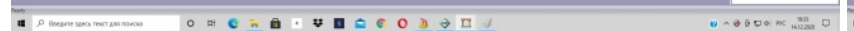

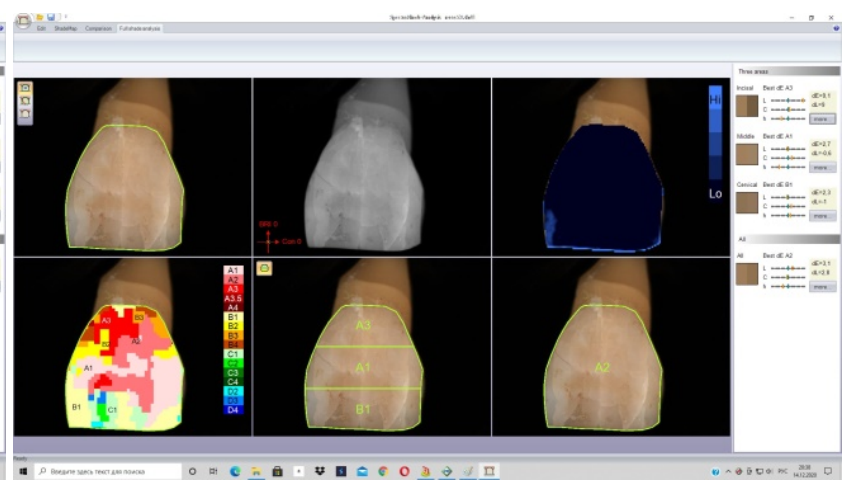

Figure 5. Shade mapping on drench tooth 2.1 from skull VIII-7-2. unable to contain data on texture. Thus our study is an attempt combine data obtained through scanning and spectrophotometry in order to improve the quality of dental reconstructions.

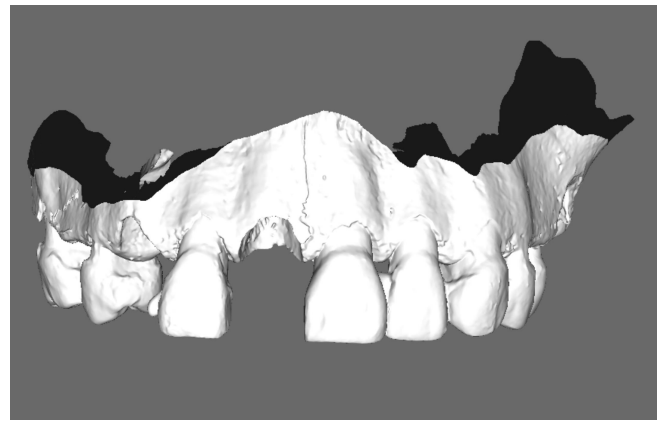

(a) 3D model of VII-7-2 jaw

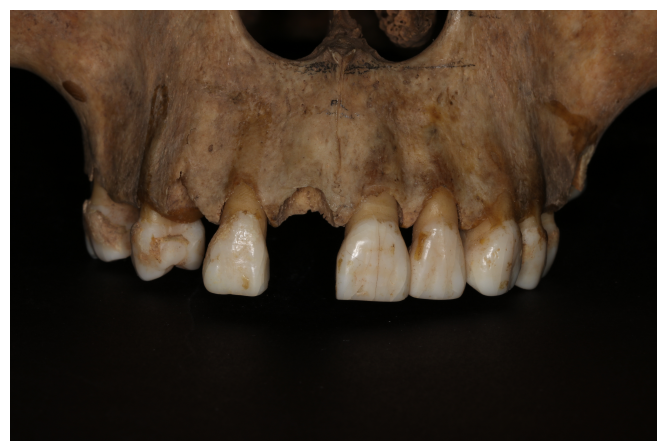

(b) an example texture image

Figure 6. Jaw 3D model obtained computed tomography and texture image.

Texture contains valuable visual information that is thoroughly used in paleoanthropology studies but mostly in separate way: 3D model is analyzed individually and object's photographs apart. Figure 6(a) presents the 3D model of VII-7-2 jaw, obtained by computed tomography, and Figure 6(b) gives an example of one of the images used for texturing.

A technique is developed for automatic creating accurate textured 3D models using as input an untextured object's 3D model and an arbitrary set of its photographs.

Two approaches are proposed, depending on the available set of texture images.

3.2.1 Feature based texturing. If a set of texture images contains a few images and is not sufficient for 3D model reconstruc- tion using Structure-from-Motion and Multi View stereo techniques, individual images are oriented in 3D model system of coordinates. To perform orientation procedure a set of corresponding points in the object's 3D model and in the its image is required. This problem is solved by detecting corresponding features in the texture image and the image of the 3D model (Lowe, 2004, Burger, 2016), that acquired by virtual camera form approximately the same point as the photograph. Figure 7 shows the results of texturing for 3D model of VII-7-2 jaw, performed by this technique.

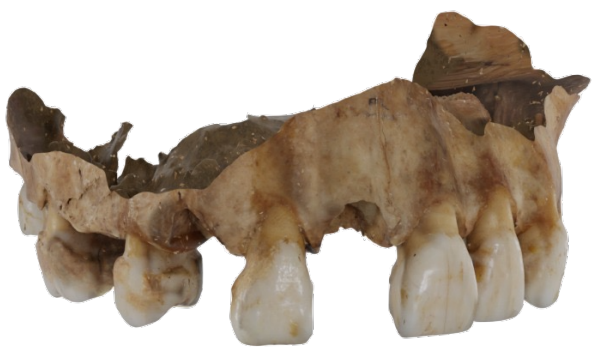

Figure 7. Textured 3D model of VII-7-2 jaw.

In the case of automatic corresponding features detection fails, texture mapping is performed according to corresponding points on teeth arch 3D models and colour image marked by operator (Knyaz, 2012).

3.2.2 3D model based texturing. For a set of texture images, specially acquired for Structure-from-Motion and Multi View stereo $3 \mathrm{D}$ reconstruction, 3D model of the object is generated firstly using this imagery (Knyaz, 2017). Then registration of the 3D models is carried out, using the following procedure.

At first, moments of inertia are calculated for computed tomography (CT) 3D model and image based (IB) 3D model. Then the principal moments of inertia principal axes of the object are found. The largest principal axis of the CT 3D model serves as a reference to scale IB 3D model to real dimension. After that 3D model registration is performed using iterative closest point algorithm (Besl, 1992). As a result image based 3D model is translated to the system coordinate of the CT 3D model and image orientation parameters are also translated to this coordinate system. Then images, oriented relatively system coordinates of CT 3D model are used for accurate photorealistic texturing. 
Figure 8 presents the results of texturing for 3D model of VII-72-2.1 tooth, performed by this 3D model based technique.

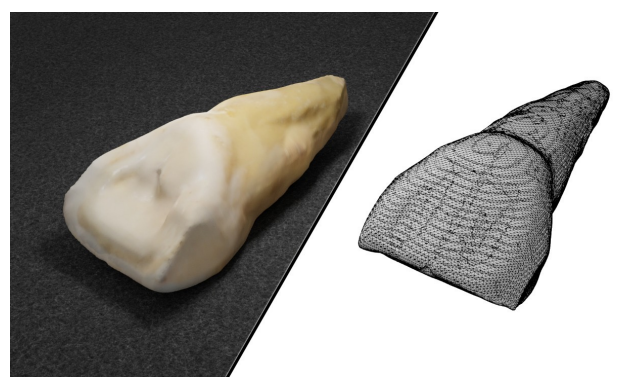

Figure 8. Textured for 3D model of VII-7-2-2.1 tooth.

Figure 9 shows the results of "prosthesis operation" using textured computed tomography 3D model of VII-7-2-2.1 tooth.

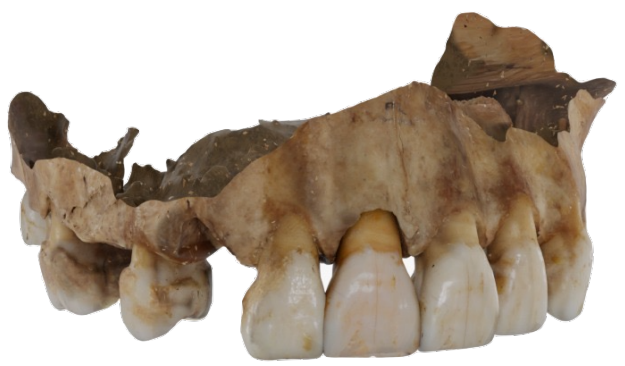

Figure 9. 3D reconstruction of the lost tooth.

Comparing with the appearance of the jaw of Figure 2, it is worth note that colour selection performed with the assistance of spectrophotometry needs to be improved from the point of view its realism

\section{CONCLUSION}

Merging study methods applied in different disciplines provides for improvements, as it can be seen on the example of combining spectrophotometric colour assessment with $3 \mathrm{D}$ reconstruction. It has been performed and described in the current paper for improvements of palaeoanthropological odontological reconstructions.

Our studies have shown that more realistic conditions achieved through drenching teeth brings to formation of more saturated shades. This can be recommended for palaeoanthropological dental reconstructions, however wider variety of teeth should be assessed for more reliable data sampling.

\section{REFERENCES}

Agrawal and Kapoor, 2013. Agrawal V.S., Kapoor S. Color and Shade Management in Esthetic Dentistry. Universal Research Journal of Dentistry. 3. 120-127. 10.4103/2249-9725.123975.

Al-Dwairi et al., 2014. Al-Dwairi Z., Shaweesh, A., Kamkarfar, S., Kamkarfar, Sh., Borzabadi-Farahani A., Lynch E. Tooth Shade Measurements Under Standard and Nonstandard Illumination and Their Agreement with Skin Color. The International journal of prosthodontics. 27. 458-460. 10.11607/ijp.3826.
Al-Nsour et al., 2018. Al-Nsour H., Al-Zoubi, T.T., Al-Rimawi, A.S. Relationship between tooth value and skin color in patients visiting Royal Medical Services clinics of Jordan. Electronic Physician. 10. 6448-6453. 10.19082/6448. Brewer et al., 2004. Brewer, J., Wee, A., Seghi, R. Advances in color matching. Dental clinics of North America. 48. v, 341-58. 10.1016/j.cden.2004.01.004

Besl, 1992. P. J. Besl and N. D. McKay, "A method for registration of 3-D shapes," in IEEE Transactions on Pattern Analysis and Machine Intelligence, vol. 14, no. 2, pp. 239-256, Feb. 1992, doi: $10.1109 / 34.121791$.

Burger, 2016. Burger W., Burge M.J. Scale-Invariant Feature Transform (SIFT). In: Digital Image Processing. Texts in Computer Science. Springer, London. https://doi.org/10.1007/978-14471-6684-9_25

Beyer, 2019. Beyer H. Photogrammetry and structured light for high accuracy data capture in the dental industry. Conference presentation. Optical 3D Metrology (O3DM), Strasbourg, 2019

Gaboutchian et al., 2020 a. Gaboutchian A.V., Knyaz V.A., Leybova N.A., Simonyan H.Y., Novikov M.M., Apresyan S.V., Cherebylo S.A., and Petrosyan G.R. 3D reconstruction and image processing of anthropological archaeological findings. Int. Arch. Photogramm. Remote Sens. Spatial Inf. Sci., XLIII-B22020, 845850, https://doi.org/10.5194/isprs-archives-XLIII-B22020-845-2020

Gaboutchian et al., 2020 b. Gaboutchian, A. V., Knyaz, V. A., Novikov, M. M., Vasilyev, S. V., Leybova, N. A., Korost, D. V., Cherebylo, S. A., and Kudaev, A. A.: AUTOMATED DIGITAL ODONTOMETRY: MEASUREMENT DATA ANALYSES IN CASES OF COMPLICATED DENTAL MORPHOLOGY, Int. Arch. Photogramm. Remote Sens. Spatial Inf. Sci., XLIII-B22020, 851856, https://doi.org/10.5194/isprs-archives-XLIII-B22020-851-2020, 2020.

Gerasimov, 1955. Gerasimov M. Vosstanovlenie lica to cerepu (In Russian). Moskva: Izdat. Akademii Nauk SSSR.

He et al., 2019. He, W.H., Park, Ch., Byun, S., Tan, D. Lin, Ch., Ralph, W., Bleak, J., Chee, W. Evaluating the relationship between tooth color and enamel thickness, using twin flash photography, crosspolarization photography, and spectrophotometer. Journal of Esthetic and Restorative Dentistry. 32. 10.1111/jerd.12553. Irish and Scott, 2015. Irish J.D., Scott G.R. A companion to dental anthropology. John Wiley \&Sons, 2016, Online ISBN: 9781118845486. DOI:10.1002/9781118845486

Joiner, 2004. Joiner A. Tooth colour: A review of the literature. Journal of dentistry. 32 Suppl 1. 3-12. 10.1016/j.jdent.2003.10.013

Joiner and Luo, 2017. Joiner A., Luo W. Tooth Colour and Whiteness: A review. Journal of Dentistry. 67S. 10.1016/j.jdent.2017.09.006

Knyaz, 2012. Knyaz, V. A., IMAGE-BASED 3D RECONSTRUCTION AND ANALYSIS FOR ORTHODONTIA, ISPRS - International Archives of the Photogrammetry, Remote Sensing and Spatial Information Sciences, XXXIX-B3, 585-589, 2012. 10.5194/isprsarchives-XXXIX-B3-585-2012.

Knyaz, 2017. Knyaz, V. and Zheltov, S., Accuracy evaluation of structure from motion surface 3D reconstruction, VIDEOMETRICS, RANGE IMAGING, AND APPLICATIONS XIV, Proceedings of SPIE, 10332, UNSP 103320P, 2017. $10.1117 / 12.2272021$ 
Knyaz et al., 2020. Knyaz V.A., Kniaz V.V., Novikov M.M., Galeev R.M. Machine learning for approximating unknown face. Int. Arch. Photogramm. Remote Sens. Spatial Inf. Sci., XLIIIB2-2020, 857862, https://doi.org/10.5194/isprs-archives-XLIIIB2-2020-857-2020

Lagouvardos et al., 2012. Lagouvardos P., Tsamali I., Papadopoulou Ch., Polyzois G. Tooth, skin, hair and eye colour interrelationships in Greek young adults. Odontology / the Society of the Nippon Dental University. 101. 10.1007/s10266-0120058-1.

Lowe, 2004. David G. Lowe, Distinctive Image Features from Scale-Invariant Keypoints, International Journal of Computer Vision, 60, 91-110, 2004

Morgan, 2012. Morgan O. Fundamentals of colour: shade matching and communication in aesthetic dentistry, 2nd edition. British dental journal. 212. 456. 10.1038/sj.bdj.2012.392.

Naidu and Freer, 2013 a. Naidu, D., Freer, T. The evidence supporting methods of tooth width measurement: Part I. Vernier calipers to stereophotogrammetry. Australian orthodontic journal. 29. 159-63

Soldo et al., 2020. Soldo, M., Ile, D., Celic, R., Knezovic, D. (). Assessment of Color Parameters on Maxillary Right Central Incisors Using Spectrophotometer and RAW Mobile Photos in Different Light Conditions. Acta Stomatologica Croatica. 54. 353362. 10.15644/asc54/4/2.

Shereen and Sameh, 2020. Shereen H., Sameh A.-S. Assessment of Tooth Shade After De-and Re-Hydration During Clinical Restorative Procedures: A Randomized Clinical Trial. Egyptian Dental Journal. 66. 2705-2714. 10.21608/edj.2020.36507.1178.

Shooriabi et al., 2016. Shooriabi, M., Gilavand, A., Yazan, M. Studying the Necessity for Presenting the Science of Determining the Tooth shade Course in Educational Curriculum in Dentistry Faculties Based on the Evaluation of the Amount of Knowledge and Performance of General Dentists. Der Pharmacia Lettre. Vol. 8. pp. 298-304, 2016.

Susanty et al., 2018. Susanty H., Gita, F., Kusdhany, L.S., Marito, P. Relationship between the color of the maxillary central incisors and age, sex, and skin color: value analysis using a spectrophotometer. Journal of Physics: Conference Series. 1073. 042009. 10.1088/1742-6596/1073/4/042009.

Tancu et al., 2019. Tancu A.M., Raileanu M., Pantea M., Totan A., Preoteasa E., Imre, M. Study on tooth shade and skin photo type correlations among dental medical students in Romania. Romanian Biotechnological Letters. 24. 1022-1026. 10.25083/rbl/24.6/1022.1026.

Zubov, 1968. Zubov A.A., Odontologiya. Metodika antropologicheskikh issledovaniy, Moscow, Nauka, 200 p. 